\title{
Pangea - The Emergence of Self
}

\author{
Jordan Grant
}

\section{ABSTRACT}

This is my story and my journey of the healing power of an arts-based child and youth care self-portrait assignment. My name is Jordan Grant, and $I$ am about to enter my final year in the Bachelor of Child and Youth Care (CYC) program at MacEwan University in Edmonton, Alberta. In my early life, I struggled to find self-acceptance and was unwilling to move into the vulnerable spaces of self-repair, as I felt overwhelmed by my perceived flaws and insecurity regarding my innate worth as a human being. The CYC program provided an uncomfortable yet safe place in which to overcome my self-doubt and experience personal growth. One third-year assignment was especially important in my personal development that $I$ have decided to share this assignment with you.

Keywords: Arts-based Education, Child and Youth Care, Self-portrait, Student

\author{
Published Online: December 10, 2021 \\ ISSN: $2736-4534$ \\ DOI : $10.24018 /$ ejedu.2021.2.6.51 \\ Jordan Grant \\ MacEwan University, Bachelor of Child \\ and Youth Care, Canada \\ (grantj46@mymacewan.ca)
}

\section{INTRODUCTION}

Often the things that make us the most uncomfortable and scared continue to call out to us. Therefore, after a break of several years, I returned to finish my Child and Youth Care (CYC) degree out of necessity. What I did not expect was that learning about CYC practice was largely a process of selfdiscovery. One of the more impactful learning experiences came in a third-year course that focused on the integration of theory, self, and ethical practice, in which students were required to complete an arts-based CYC practice self-portrait. The purpose of the assignment is to have students express their learning and personal insights regarding the concepts covered throughout the course, particularly in relation to their emerging professional identities as CYC practitioners. The assignment did not require any artistic training, as the goal of arts-based learning is not to teach CYC students to become artists but rather to create immersive learning experiences that make use of artistic processes to help students gain new insights into and perspectives on their learning experiences. The instructions for this task were simple: We were asked to select a material (e.g., papier-mâché, clay, cloth, wood, bottle) with which to create a figurative self-image and to design creative background scenes to express our thoughts, insights, and even emotions in regard to the course content. It was emphasized that the CYC practice self-portrait assignment was not about defining our CYC practice but was rather intended to serve as an illustration of how we thought about how our practices were evolving as we worked through the course material. Using digital photography, we took photographs of our figurative self-images against the backdrops we made to creatively illustrate our interpretation and personal experience of the course content. The photographs were electronically pasted into a Word document along with a short explanation; I have provided the text below.

\section{PANGEA}

When I began to think of what my project would look like, I was drawn to the history of Pangea, the land that existed before all the continents we see today. When Pangea existed, the world was one - one landmass, one ocean, one place that ultimately became all that the world is today. Pangea became a metaphor that I would base the entirety of my project on. As with everything in life, our versions of Self are also adapting, changing, and constantly evolving. With this fact in mind, I began to reflect on what I had grown from. During this time of reflection, I was also undergoing an intensive time in therapy. Through therapy and this project, the idea of a miniature Jordan came to be (see Fig. 1).

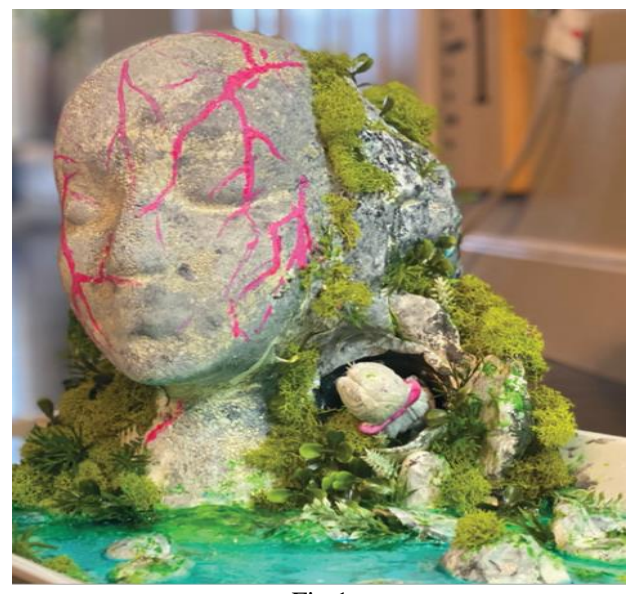

Fig.1. 
In therapy, I referred to this miniature version of myself and the child in me as someone who had been lost and yearned to surface through the trauma and repression, I had experienced in my earlier life The amalgamation of these two ideas led to the following artwork and journey through which I discover myself, and, more importantly, the concept of nonself. Through this journey, I began to understand the importance of accepting and living life instead of hiding in the shadows of fear and trauma. The first year of the CYC course showed me that I was not ready to be a changemaker in the world, but I failed to understand that there is a difference between not being prepared and being incapable. The subsequent years were some of the most joyful but also some of the darkest times in my life, yet through all this period the nagging feeling that I was simply incapable of happiness or creating the change that I wanted so desperately to see plagued it all. When, out of necessity, I returned to complete my second year in order to support my young family, I still believed I was simply Jordan, nothing more but certainly less than what people perceived me to be.

\section{A. Paradigms}

When Pangea first fractured, two continents were created. This was referred to as the Permian period. The oceans began to shift to make room for this new version of the world. This change is represented by the hole the small figurine emerges from. This miniature figurine represents individuals' journeys as they become a part of the world, in the form of Self (see Fig. 2). As with the evolution of the world and the significant shifts in the landscape that created the world we know today, Self moves through the Triassic, Jurassic, and Cretaceous periods to reach the present. The things that have shaped me turned me into the person I am today and became the foundation of my entire life. I have been affected by those who came before me, my environments, and my decisions, both internal and external. However, just as Pangea fractured to create the different plates of the world, so have I. As I grow, embracing my most authentic Self, fractures form in the foundation. A new part of myself emerges. This new part of me, while minor, is nonetheless inconsequential. This smaller version of me can move through space and time, absorbing the knowledge that comes with observation and exploration. As this fractured part of myself becomes confident in its own individuality and ability to be in the world, the bond between Pangea and me continues to fracture. Still, with every fracture, a robust attachment occurs, linking Self to the beginning.

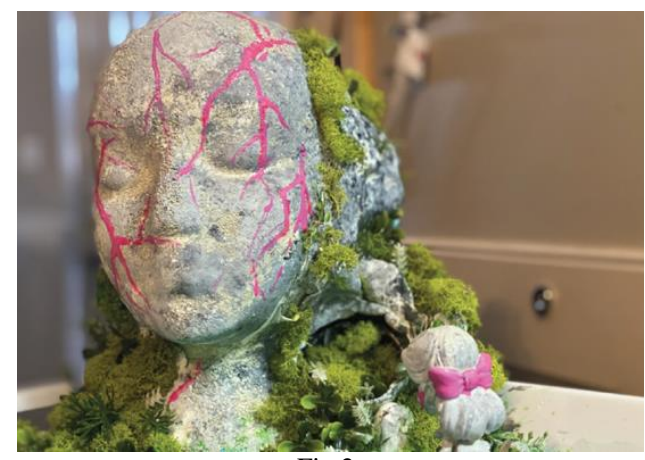

Fig 2.
Throughout this assignment I tapped into memorable experiences from the first and second year of the program. The use of masks to create the headlands was directly inspired by an experience in the first year of the course in which we used masks to represent what people saw and what we kept close to ourselves. This assignment was an integral part of why I left the CYC program in the first place. Combining the two assignments brought a sense of closure to me as I felt a chapter characterized by inability ending and one characterizes by success beginning. The breath I refer to throughout this article is a reference to another assignment completed for this course, which took the form of a music video in which I discussed remembering to breathe. Finally, the use of my literal and figurative selves meeting came from a germline assignment we had completed previously, in which we used art to express what holds us back as practitioners.

\section{TRIASSIC}

The first of the significant fractures represents the ability to live myself in search of Self. A new headland appears. Self begins this journey and approaches this new mass. The journey to reach it is hard and requires the Self to become aware of the surroundings and impacts of Pangea. As Self comes, the mass appears to be a reflection that Self has seen in the water. Self is cautious but curious. The mouth is unable to make a sound or acknowledge that Self approaches (see Fig. 3).

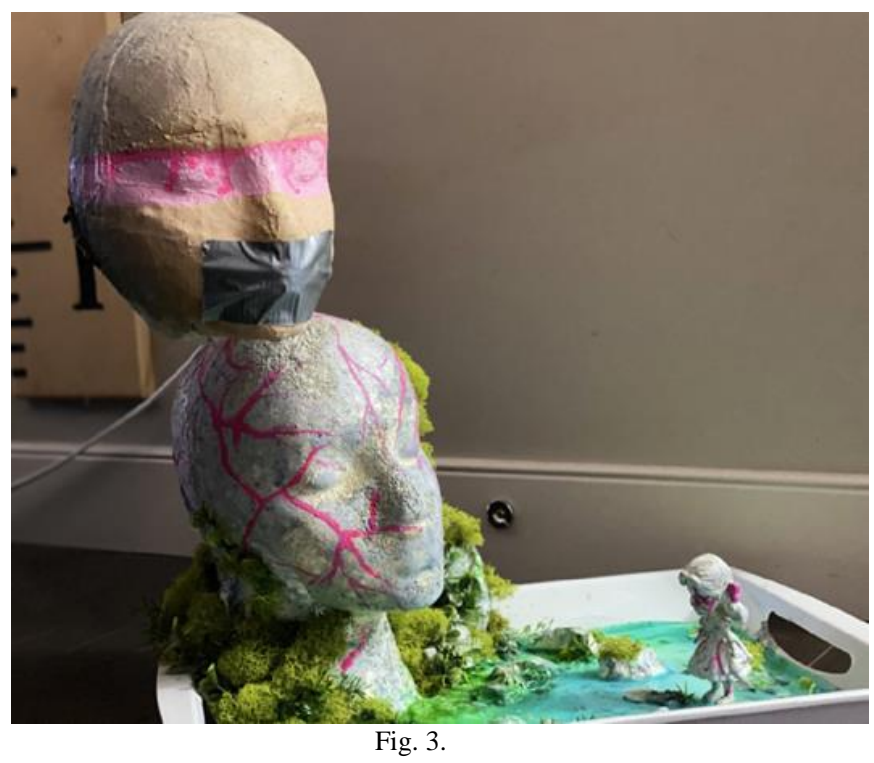

The knowledge starts to flow into Self. The red represents the foundation where all beliefs emerge from, the central view (see Fig. 4). As view mutates and the Self becomes more cognizant of the ideals and things around us, the central brain expands, creating more room for knowledge, understanding, growth, acceptance, adaption, and empathy. 


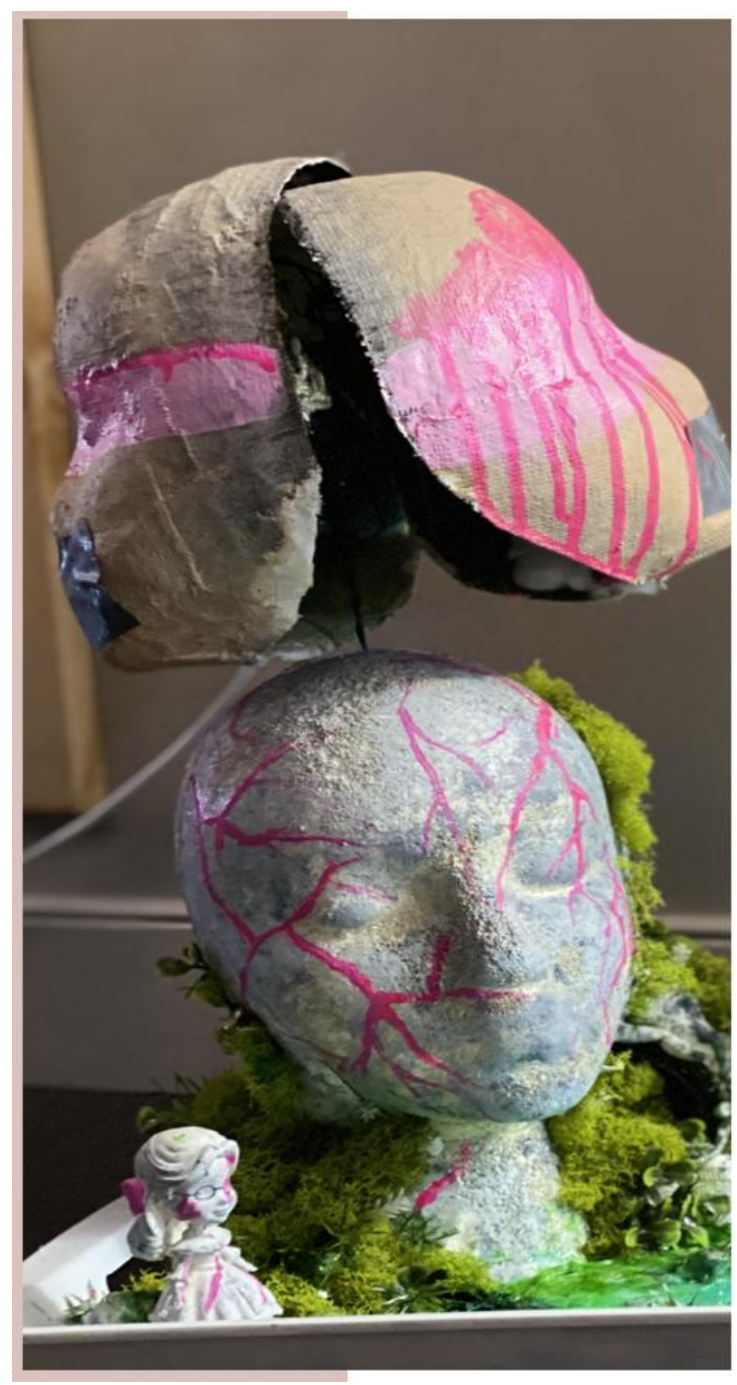

Fig.5.

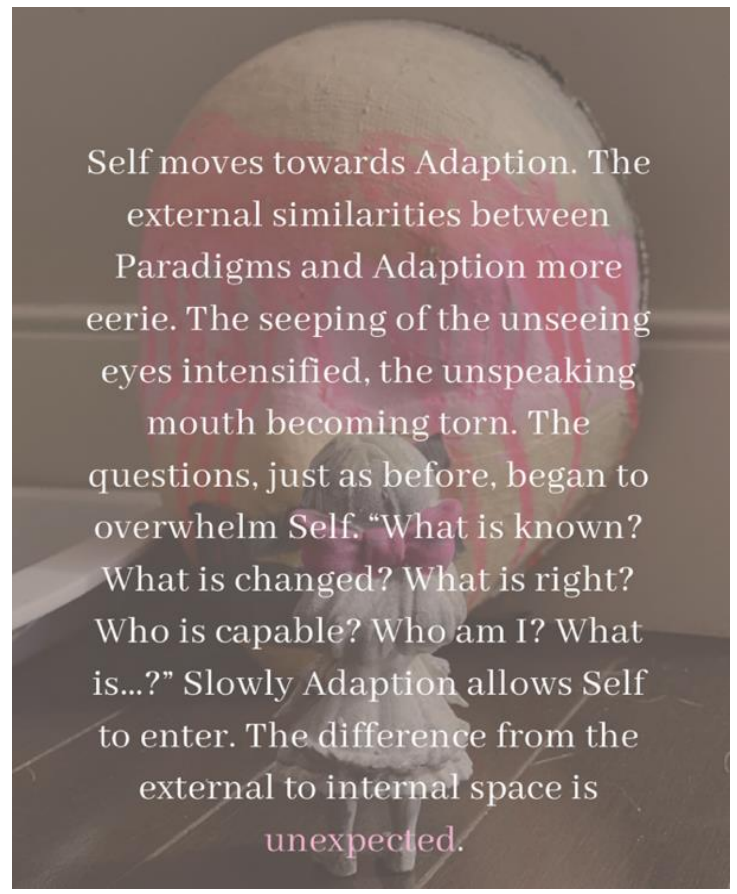

Fig. 6. 


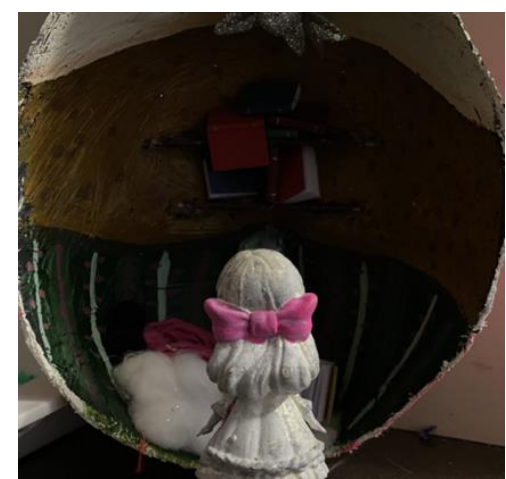

Fig 7.

Self is comforted by the space presented. Paradigm showed the explosion of knowledge, the foundations, whereas this space invited knowledge. The quivering of the headlands ceased; Adaption seemed to invite Self into the mass. As Self embraces what Adaption has to share, the books of knowledge appear. Each of these books is full of stories and frameworks from those who were the past keepers. Each story represents a different view on the world and contains different knowledge regarding existence and the ability to change. As Self absorbs these teachings, Self begins to change (see Fig. 7 above).

The questions from before are answered, yet more continue to arise. "What is change? Am I change? Is change possible?" Though Self feels as though there is much left to learn, learning comes with immersion. A bridge forms between Knowing, Being, and Doing. As this revelation fills the space, Adaption seems to make it known to Self that it is time to move forward (see Fig. 8). There is more to learn. Pangea echoes this; the quivering begins to intensify. A new headland appears.

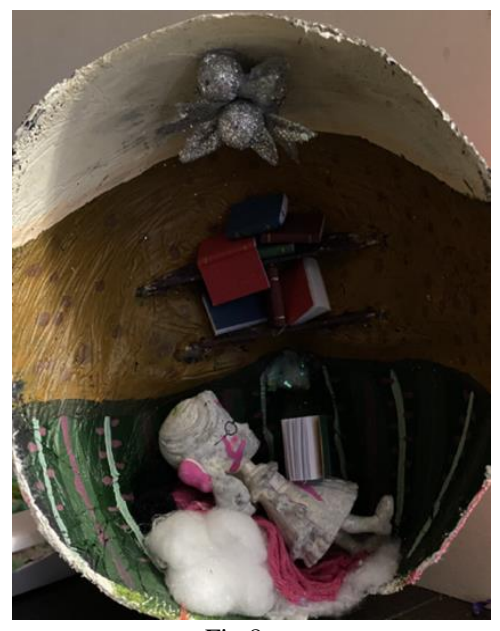

Fig 8 .

\section{CRetaceous}

As before, this new headland hovers above Pangea. The quivering intensifying as this third mass reaches its final position. Though Once settled, Pangea seems to release its breath, uttering this new name. This name, which seemed confusing, sounding different each time the wind carried it, a language unfamiliar to Self (see Fig. 9). Self turns their head. The quivering of Pangea and the headlands becoming violent.

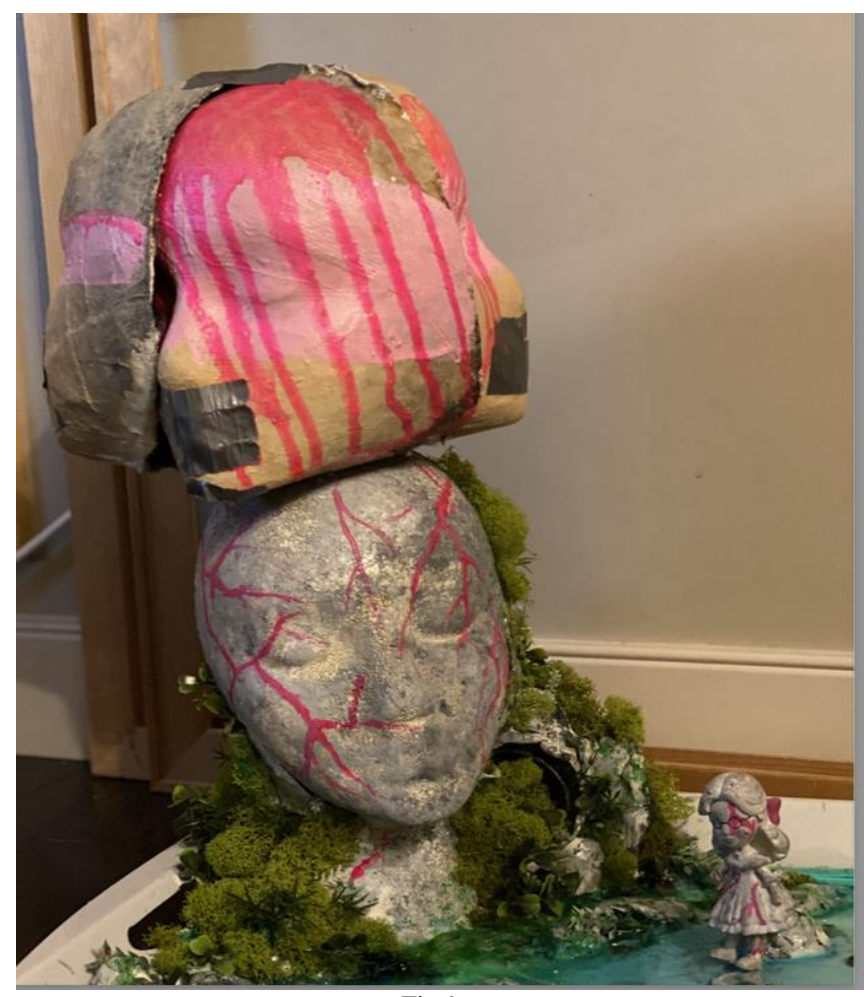

Fig 9.

This third headland, Beusòlas urges Self to move towards the chaos. The sleeping eyes taking over the entirety of the face, perhaps knowledge overflowing from within, the once unspeaking mouth held shut by almost nothing. The questions that begin to flood Self as they approach Beusòlas are unclear. Self-serving? Self-protecting? Unskilled? An overwhelming sense of anxiety fills Self. Pangea seems to sense this in Self, and the quivering again ceases (see Fig. 10).

Seemingly satisfied, Beusòlas allows Self to enter. The internal walls of this headland are thin compared to those of the other headlands. The black and white walls of Beusòlas become greyer. Unlike before, the questions are not answered. As Self spends more time immersed in this space, the more arguments Self seems to create within Beusòlas (see Fig. 11).

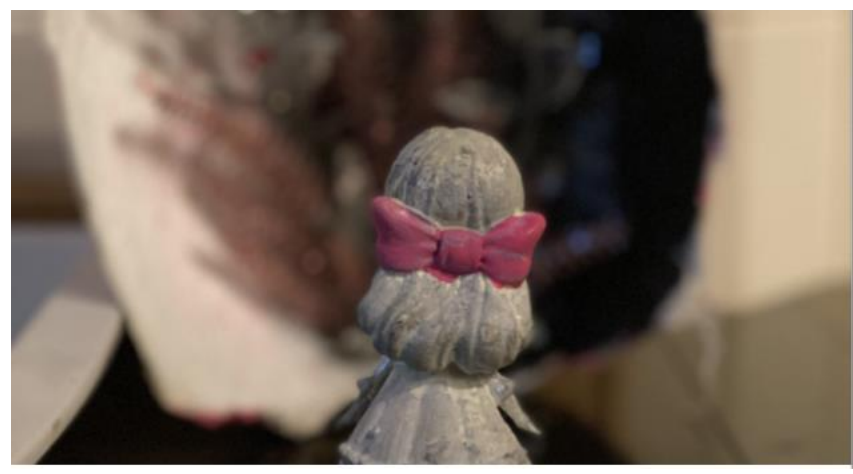

Fig 10. 


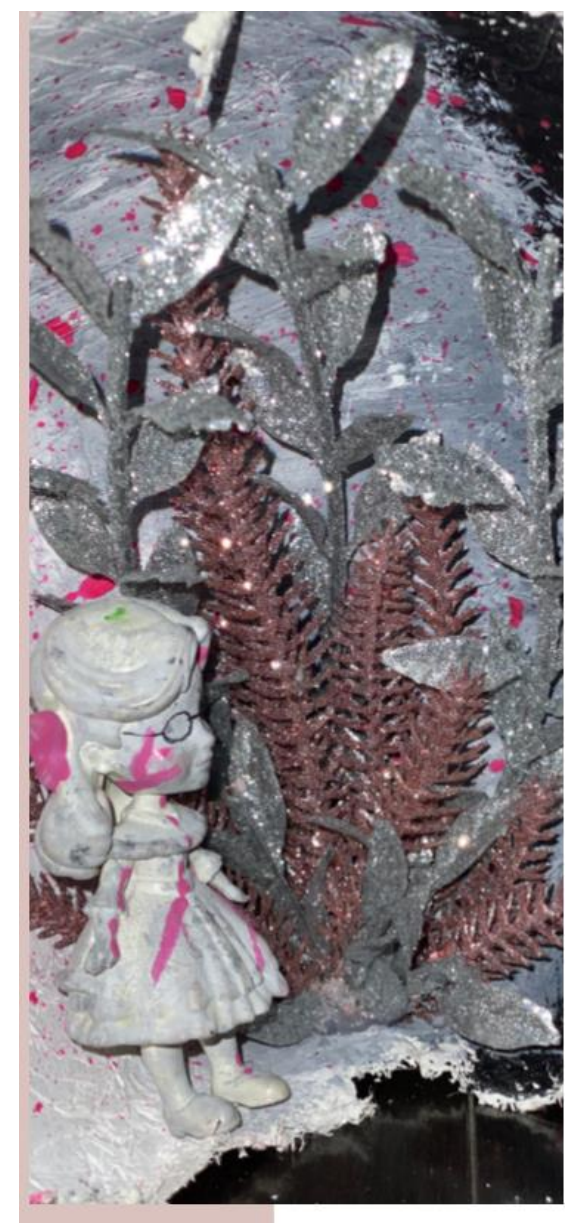

Fig 11.

Frustration and anxiety continue to overcome Self. Without warning, Pangea lets out a terrifying scream. The swirling chaos inside Beusòlas ceases. The anxiety and frustration within Self leave as abruptly as they entered. Self stands in stunned silence (see Fig. 12). Unlike the other headlands, this one created pain, a feeling of being incapable, having no answers, and being unable to make the right decision. Slowly, Pangea begins to break. This time, there was no quivering but a breath that carried voices. These voices shared Self's knowledge, experiences, pain, sorrow, joy, achievements. Beusòlas, hearing these voices, release Self, sending them on the next journey. Not before Beusòlas utters one last message "My name is Ethics, named in the tongue of your ancestors." This time, however, no new headland appears. Nothing changes. It is evident, though, that there is something more. Self begins to journey down towards the water, wondering whether they had missed something at the point where the journey began. Self-completes the descent and curiously approaches the spot from which they first emerged. As Self peers into ontology, the answer appears.

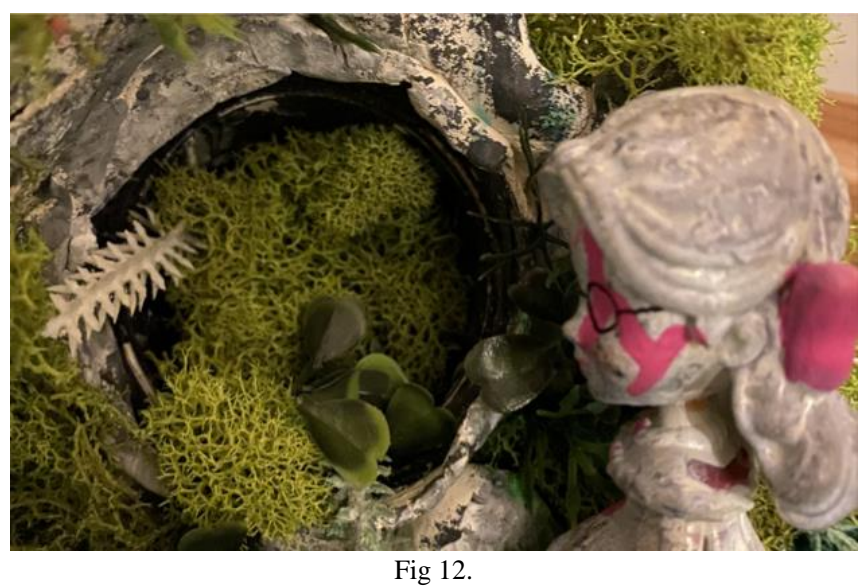

\section{PRESENT}

This hidden identity where Self crawled from mimics the headlands, Pangea, and Self. The fractures of the journey that Self has undergone show within this face. The change in this identity is apparent, however. The eyes that were unseen in the headlands are wide open, with knowledge seeping from them. The mouths that were bound, preventing sound from escaping from them, are free. Fractures riddle the skin of this identity again. As Self and this identity meet, the headlands crumble to rest with Pangea. This identity takes a breath, slowly releasing it as they speak. I am Jordan. I am Self. Self is me. Our journey has just begun.

This is my journey so far, but I am still learning and discovering many things in Canada. The most important thing that I have learned so far is when you are facing a problem, "you must speak" because that is the only way you to escape. Change comes when we are willing to use our voices and vision not only to call attention to injustice, inequality, and inequity but also to celebrate the good in the world. I am still unsure as to what I bring to the world of CYC; what I do know, however, is that the parts of me that I repressed and buried deep down are what bring light to my work. I know that I am a force, a changemaker who has just begun to awaken (see Fig. 13). Antipathy is being replaced with selfcompassion.

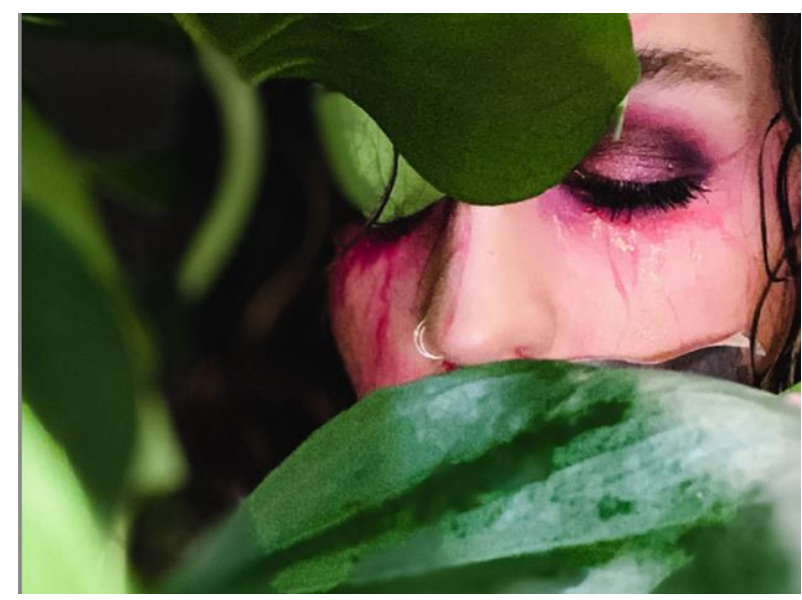

Fig 13. 
With that, I thank you for taking the time to enter this space of learning and vulnerability. The world we live in has been home to countless catastrophes and changes but has evolved to create a space in which humanity can thrive and sustains a wide variety of life. Similarly, I have a journey to become Jordan - a mother, a practitioner, a partner, and a friend, but most importantly, myself.

The weather is pleasant, cold, and rainy. The sadness that comes with the warm weather leaving also brings a reminder that after the darkness new life begins. I am looking forward towards the winter now, the beauty that comes with sparkling snow and the magic of holidays. With that, I wish you all very good luck, health, safety and a successful year ahead (see Fig. 14).

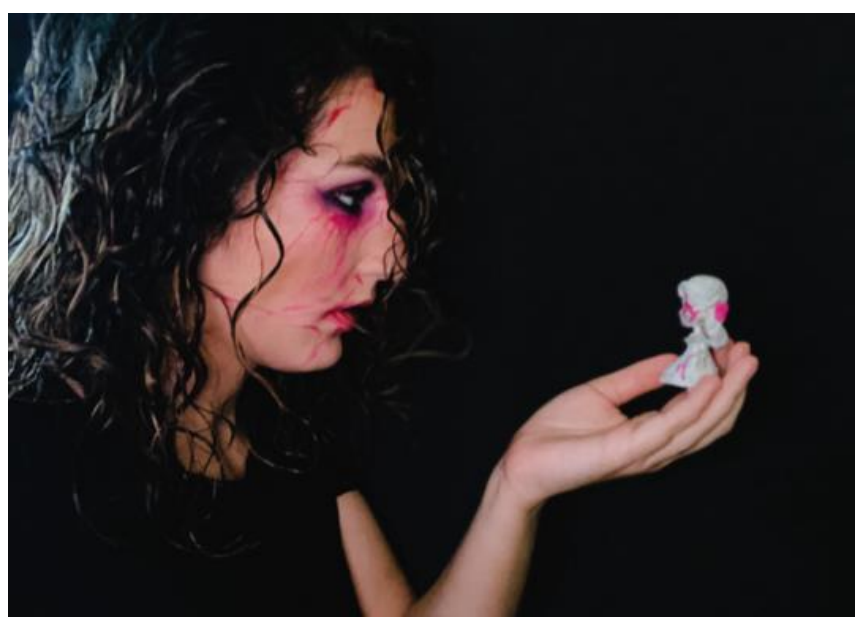

Fig 14.

\section{ACKNOWLEDGMENT}

Thank you to Dr. Gerard Bellefeuille for believing in me and encouraging me throughout this journey. Thank you for your help with the editing and development of this article and for giving me space to find my "self."

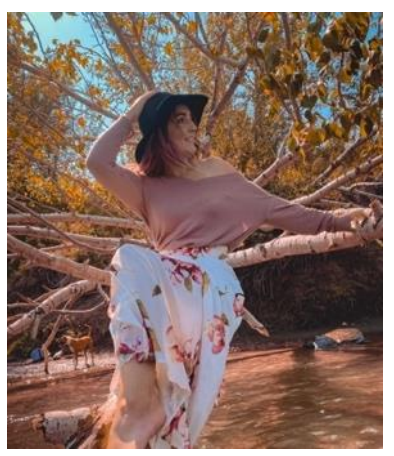

Jordan Grant is in her final year of Child and Youth Care at MacEwan University. Jordan hopes to purse higher education to fulfill her dreams of working in art and play therapy, as well as in academia. Jordan has special interests in research, advocacy, somoesthics. Currently Jordan is supporting her children through the COVID-19 pandemic but homeschooling them alongside her final year of studies and placement. 